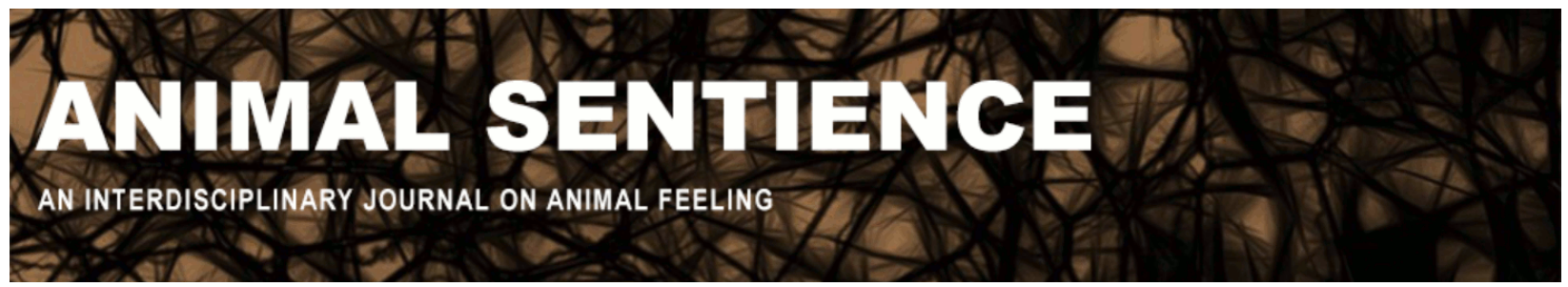

Fitzpatrick, Simon (2020) Avoiding anthropocentrism in evolutionarily inclusive ethics. Animal Sentience 29(29)

DOI: $10.51291 / 2377-7478.1611$

Date of submission: 2020-07-02

Date of acceptance: 2020-07-17

(c)

This article has appeared in the journal Animal

Sentience, a peer-reviewed journal on animal

cognition and feeling. It has been made open access,

free for all, by WellBeing International and deposited

in the WBI Studies Repository. For more information,

please contact

wbisr-info@wellbeingintl.org.

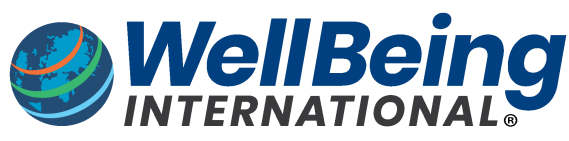

SOLUTIONS FOR PEOPLE, ANIMALS AND ENVIRONMENT 


\title{
Avoiding anthropocentrism in evolutionarily inclusive ethics
}

Commentary on Mikhalevich \& Powell on Invertebrate Minds

\author{
Simon Fitzpatrick \\ Department of Philosophy, John Carroll University
}

\begin{abstract}
Mikhalevich \& Powell are to be commended for challenging the "invertebrate dogma" that invertebrates are unworthy of ethical concern. However, developing an evolutionarily inclusive ethics requires facing some of the more radical implications of rejecting hierarchical scala naturae and human-centered conceptions of the biological world. In particular, we need to question the anthropocentric assumptions that still linger in discussions like these.
\end{abstract}


Mikhalevich \& Powell (2020) (M\&P) make a good case for calling into question the "invertebrate dogma" of ignoring invertebrates (especially arthropods) as potential subjects of ethical concern. M\&P's case is built on evidence of convergent evolution for cognitive capacities, including sentience. in vertebrates and a diverse variety of invertebrates. This evidence suggests that to be consistent with the treatment of vertebrates many invertebrates are candidates for welfare consideration. However, like Monsó \& Osuna-Mascaró (2020), I have some concerns about this consistency approach. Like Figdor (2020 and forthcoming), I think an evolutionarily inclusive ethics requires facing some of the more radical implications of rejecting hierarchical, scala naturae and human-centered views of the biological world. In particular, we need to question lingering anthropocentric assumptions.

In animal ethics we are frequently concerned with questions about how we as human beings should behave toward other species and what our ethical obligations toward them may or may not be. This makes sense because we can only make ethical decisions for ourselves. However, a form of ethical anthropocentrism is still there when we frame these questions in terms of our granting moral status to them, as if we have some special authority or ownership over moral status-either that we are the ones who get to grant it, or, more often, that we are the measure of it. Despite commitment to secularism and Darwinism, this way of thinking is implicit in much of the animal ethics literature, and M\&P seem to adopt it, too, by pursuing the standard strategy of pointing to apparent cognitive and other similarities between various invertebrates and adult human beings. This is fine, as far as it goes, for getting reluctant human beings -- with their anachronistic assumptions about invertebrates and cognitive-affective biases M\&P describe -- to even consider invertebrates as potential subjects of ethical concern. But 
Monsó \& Osuna-Mascaró point out the numerous problems with extending standard "wideningthe-circle" approaches in animal ethics to the radically un-human-like ways of life of many invertebrate species. If ants or termites matter ethically, that can't be because we can fit them neatly into individualistic welfare-centered ethical theories modelled on human beings.

As Figdor (2018, 2020, forthcoming) argues, abandoning a human-centered scala naturae also entails abandoning the assumption that similarity to human beings should be the standard for judging other species -- both their cognitive capacities and their moral status. This is easy to see using Woodhall's (2015) analogy between anthropocentrism (Kopnina et al. 2018) and androcentrism. The strategy of beginning with human beings, identifying traits that confer moral status on us, and then expanding this outward to other species that share the relevant traits is analogous to taking (white) cisgendered males as the normative standard and expanding outward to other human beings in terms of how they measure up to that standard.

A non-human-centered, evolutionarily inclusive ethics needs to reject the notion that human beings are the measure of all things. We need to question common intuitions about what matters ethically and to be more humble about our understanding of the nature and scope of ethical value: What we as human beings typically take to be of ethical concern need not exhaust all that is of ethical concern; what we typically care about need not be all that should be cared about.

This has implications for the notion of moral status. Our parochial intuitions about what might distort our view about which organisms are worthy of ethical concern just as much as the cognitive-affective biases M\&P describe. I hence agree with Levy (2020) that we should not take it for granted that sentience is necessary for moral status. The same applies, however, to Levy's proposal that it is cognition, not sentience, that is necessary. Neither may be necessary. This is not to say that sentience and cognition don't matter, or that there aren't good arguments for emphasizing sentience as a basis for moral status; it is just that we need to reflect more on why we should take sentience (or whatever it is) as the measure for moral status and be sure we are not simply assuming that our own species is the moral yardstick.

Similar issues arise about the practical implications of including invertebrates in our ethical deliberations. Browning \& Veit (2020) are quite right that acknowledging the moral status of invertebrates needn't necessarily entail radical changes to human behavior. However, we must be careful not to settle for rationalizations based on human-centered conceptions of what is "too demanding". Ethical revolutions may appear "too demanding" for those whose practices come into question; so we do have to take it seriously that understanding our moral obligations to invertebrates may have quite radical implications for human practices. Some (e.g., Carruthers, 2007) take anything that would entail radical changes in human behavior as evidence that conclusions like those of M\&P are absurd. This shows how blatant human anthropocentrism can be; but we need to be careful to avoid the more subtle forms of anthropocentrism, too.

\section{References}

Browning, H. \& Veit, W. (2020). Improving invertebrate welfare. Animal Sentience 29(4).

Carruthers, P (2007). Invertebrate minds: A challenge for ethical theory. The Journal of Ethics 11(3): 275-297. 
Figdor, C. (2018). Pieces of mind: The proper domain of psychological predicates. Oxford University Press.

Figdor, C. (2020). Relationship between cognition and moral status needs overhaul. Animal Sentience 29(3).

Figdor, C. (forthcoming). The psychological speciesism of Humanism. Philosophical Studies.

Kopnina, H., Washington, H., Taylor, B., \& Piccolo, J.J. (2018). Anthropocentrism: More than just a misunderstood problem. Journal of Environmental \& Agricultural Ethics 31: 109-127.

Levy, N. (2020). It might not matter very much whether insects are conscious. Animal Sentience 29(2).

Mikhalevich, I., \& Powell, R. (2020). Minds without spines: Evolutionarily inclusive animal ethics. Animal Sentience 29(1).

Monsó, S., \& Osuna-Mascaró, A.J. (2020). Problems with basing insect ethics on individuals' welfare. Animal Sentience 29(8).

Woodhall, A. (2015). Anthropocentrism and issues facing nonhuman animals. In D. Moorehead (ed.), Animals in human society: Amazing creatures who share our planet. University Press of America. 